\title{
Transcatheter intervention in carotid artery disease: when and how?
}

\author{
Tomislav Jakljević* \\ University of Rijeka School of Medicine, University Hospital Centre Rijeka, Rijeka, Croatia
}

\begin{abstract}
Carotid artery disease, due to atherosclerotic changes and consequent stenotic lesion, is responsible for about $20 \%$ of all ischemic strokes. Rare causes of carotid stenosis are irradiation therapy, vasculitis, accidental dissection or fibromuscular dysplasia. Its impact on public health and patient's quality of life is considerable and causes long-term disability.

In general population, in $5.7 \%$ of patients between 70 and 80 years of age and $9.5 \%$ of patients over 80 years of age, carotid stenosis over $50 \%$ is diagnosed. Carotid stenosis can be asymptomatic or diagnosed when TIA (transient ischemic attack) or cerebral stroke occurs (symptomatic). In patients with symptomatic carotid stenosis, the risk of recurrent stroke is much higher.

Carotid stenosis could be easily and promptly diagnosed with Doppler ultrasound, CT scan or MR imaging. The de-

\author{
Received: $22^{\text {nd }}$ Apr 2014 \\ *Address for correspondence: Klinički bolnički centar Rijeka, Tome Strižića 3, HR- \\ 51000 Rijeka, Croatia. \\ Phone: +385-99-6726-469 \\ E-mail: tomislav.jakljevic@gmail.com
}

gree of stenosis, morphology and homogeneity of adjacent plaque, presence of thrombus, intracranial pathologies and asymptomatic cerebral embolic events must be evaluated.

Optimal medical treatment has to be provided to patients, both with symptomatic and asymptomatic carotid stenosis. Antiplatelet and statin therapy should be administered to all patients, irrespective of symptoms or disease progression. Risk factors (arterial hypertension, diabetes, obesity, smoking etc.) must be recognized and promptly cured.

Although many large scale trials (CAVATAS, EVA-3S, ICSS, SAPPHIRE, CREST, etc.) recognize carotid endarterectomy advantages in the treatment of carotid stenosis, carotid stenting as a revascularization option has its place in certain subgroups of patients. The patients with high perioperative risk, infavourable neck anatomy, prior neck dissection, restenosis after carotid endarterectomy or post-irradiation stenosis benefit from transcatheter interventions. The aim of this research is to explore the indications and to detail the most used techniques in carotid artery stenosis transcatheter interventions.

KEYWORDS: carotid artery disease, stenosis, treatment. CITATION: Cardiol Croat. 2014;9(5-6):184.

\section{Literature}

\footnotetext{
1. Grau AJ, Weimar C, Buggle F, et al. Risk factors, outcome and treatment in subtypes of ischemic stroke: the German stroke data bank. Stroke. 2001;32:2559-66.

2. Petty GW, Brown RD, Jr., Whisnant JP, Sicks JD, O'Fallon WM, Wiebers DO. Ischemic stroke subtypes: a population-based study of incidence and risk factors. Stroke. 1999; 30(12):2513-6.

3. European Stroke Organisation, Tendera M, Aboyans V, Bartelink ML, et al; ESC Committee for Practice Guidelines. ESC Guidelines on the diagnosis and treatment of peripheral artery diseases: Document covering atherosclerotic disease of extracranial carotid and vertebral, mesenteric, renal, upper and lower extremity arteries: the Task Force on the Diagnosis and Treatment of Peripheral Artery Diseases of the European Society of Cardiology (ESC). Eur Heart J. 2011;32:2851-906.
} 